\title{
Uma crítica feminista da segurança pública no enfrentamento à violência contra mulheres
}

\author{
A feminist critique of the public security response to violence against women
}

\author{
Milena Fernandes BARROSO* \\ https://orcid.org/o00o-0002-8349-1508
}

Raissa Ribeiro LIMA**

https://orcid.org/o0oo-00o1-6213-3907

\begin{abstract}
Resumo: $\mathrm{O}$ artigo discute, a partir da criminologia crítica feminista, o enfrentamento à violência contra as mulheres pela segurança pública. Na primeira parte, apresentamos um breve debate sobre a segurança pública na atualidade, com destaque para as contradições e desafios em torno da criminalização da violência contra as mulheres. Na segunda, analisamos os dados de pesquisa nas instituições de segurança pública realizada no munícipio de Parintins, Amazonas, no ano de 2019, com vistas a apreender a dinâmica do atendimento às mulheres em situação de violência. O estudo aponta a necessidade e importância da crítica feminista às medidas punitivistas no enfrentamento à violência, bem como reafirma o descaso das instituições de segurança na proteção às mulheres, ainda que essas se constituam como principal porta de entrada aos demais serviços de atendimento a casos desta natureza. Palavras-chave: Violência contra a mulher. Segurança pública. Criminologia crítica feminista. Parintins. Amazonas.
\end{abstract}

Abstract: From the perspective of critical feminist criminology, this article discusses how public security institutions are addressing violence against women. In the first section, we present a brief debate on current issues of public security, highlighting the contradictions and challenges surrounding the criminalization of violence against women. Next, we analyze research data collected in 2019 from the public security institutions of the city of Parintins, Amazonas, to understand the dynamics of assistance for women at risk of violence. The study points out the need for and importance of a feminist critique of punitive measures in the fight against violence, as well as reaffirming the neglect of these institutions in protecting women, even though they are the primary gateway to other related care services.

Keywords: Violence against women. Public security. Critical feminist criminology. Parintins. Amazonas.

Submetido em: 29/6/2020. Revisado em: 25/9/2020. Aceito em: 18/10/2020.

\footnotetext{
* Assistente social. Doutora em Serviço Social. Professora do Programa de Pós-Graduação em Serviço Social e Sustentabilidade e do curso de Serviço Social da Universidade Federal do Amazonas. (UFM, Manaus, Brasil). Av. General Rodrigo Octávio, 6200, Coroado I, Prédio da Reitoria, $1^{0}$ andar, Setor Norte do Campus Universitário, CEP 69080-900, Manaus (AM). E-mail: mibarroso@yahoo.com.br.

** Assistente Social. Pesquisadora pela Fundação de Amparo à Pesquisa do Estado do Amazonas (Fapeam, Manaus, Brasil). Av. Prof. Nilton Lins, 3259, Flores, Manaus (AM), CEP 69058-030. E-mail: raissaribeirolima15@gmail.com.
} copiar e redistribuir o material em qualquer suporte ou formato, bem como adaptar, transformar e criar a partir deste material para qualquer fim, mesmo que comercial. O licenciante não pode revogar estes direitos desde que você respeite os termos da licença.

Argum., Vitória, v. 12, n. 3, p. 69-85, set./dez. 2020. | ISSN 2176-9575 


\title{
Introdução
}

\begin{abstract}
A violência contra as mulheres não é mais um tabu. Não sem tensionamentos e a questão tem sido reconhecida e seus efeitos e consequências foram/são denunciados pelos movimentos de mulheres e feministas (BARROSO, 2018). Na década de 1970, o fenômeno passou a ser discutido de forma mais ampla, tornando-se tema central desses movimentos em suas reivindicações nas décadas posteriores. Nos anos de 1980, grupos feministas começaram a se organizar com outros movimentos no combate à violência contra as mulheres, cobrando do Estado mecanismos que amparassem as mulheres em situação de violência. Em 1985, em resposta a estas manifestações, foi criada em São Paulo a primeira Delegacia de Defesa à Mulher (DDM).
\end{abstract}

A criação da delegacia especializada no Brasil foi uma experiência pioneira no mundo, e desde sua instalação tem ocupado posição central nos debates sobre o enfretamento à violência contra as mulheres. Avança-se, portanto, na criminalização dessa violência no país. Entretanto, apesar da mobilização social em torno da questão e da inegável luta das mulheres para as mudanças nas legislações, das novas práticas sociais de prevenção à violência e proteção às vítimas, a violência contra as mulheres parece não dar tréguas (BARROSO, 2018), e nos coloca questões em torno das contradições e limites das medidas punitivistas e do discurso da impunidade como grande vilã e determinação da violência.

Nas últimas três décadas, o debate sobre violência contra as mulheres e segurança pública ampliou-se de modo que o poder público e a comunidade acadêmica têm sido chamados a debater e problematizar esses temas. Isto se intensifica atualmente, em um contexto de retrocesso no campo das políticas públicas para as mulheres. Neste sentido, destacamos a importância da produção científica nessa área pois, além da segurança pública se manifestar como umas das principais demandas sociais (dadas as taxas de vitimização do país ${ }^{1}$ ), é também um dos principais campos de estudo em várias áreas do conhecimento, implicando em uma multiplicidade de abordagens. Este fato, além de contribuir para a reflexão sobre o atendimento às mulheres pela segurança pública, pode fornecer subsídios para a construção de medidas de proteção a essas que extrapolem as fronteiras das instituições.

Neste artigo, tendo como inspiração os debates da criminologia crítica feminista ${ }^{2}$, analisamos o atendimento às mulheres em situação de violência pelas instituições de

1 Os dados do documento Agenda Segurança Pública é solução, lançado em agosto de 2018, pelo
Fórum Brasileiro de Segurança Pública, Instituto Sou da Paz e Instituto Igarapé, apontam que
62.517 homicídios ocorreram em 2016 no Brasil; à época, 123 cidades concentravam $50 \%$ dos
homicídios ocorridos no país; 44.475 foi o número de mortes por armas de fogo em 2016, mais de 70\%
do total; 49.497 casos de estupro foram registrados no mesmo ano; a cada duas horas, uma mulher é
assassinada no Brasil; houve 106,53 mortes de policiais a cada 10o mil que estão na ativa por ano;
4.223 pessoas morreram em decorrência de ações policiais em 2016; 726.712 pessoas
estavam presas em 368.049 vagas naquele ano - uma taxa de ocupação de $197 \%$ (RESENDE, 2018).
2 A Criminologia Crítica Feminista é um pensamento que visa trazer para o centro dos estudos
criminológicos a perspectiva das mulheres, tentando subverter um sistema legal a partir do ponto de
vista de que o sistema penal (centrado no 'homem' - androcêntrico -, que invariavelmente produziu o
que a criminologia feminista identificou como dupla violência contra a mulher): 1) invisibiliza ou

Argum., Vitória, v. 12, n. 3, p. 69-85, set./dez. 2020. | ISSN 2176-9575 
Segurança Pública que ofertam serviços especializados e não especializados às mulheres vítimas de violências no município de Parintins ${ }^{3}$, quais sejam: Delegacia Especializada em Crimes contra a Mulher (DECCM), $3^{\underline{a}}$ Delegacia Interativa de Polícia ( $3^{\underline{a}}$ DIP), $11^{\underline{0}}$ Batalhão de Polícia Militar ( $11^{\circ}$ BPM) e Instituto Médico Legal (IML). Os dados foram obtidos por meio de pesquisa empírica em fevereiro de 2019, através da realização de visitas institucionais e entrevistas ${ }^{4}$ com 4 (quatro) profissionais da Segurança Pública que representam as referidas instituições: 1 (uma) delegada de polícia (DECCM), 1 (um) delegado de polícia ( $3^{\underline{a}}$ DIP), 1 (um) tenente-coronel (11ํㅡㄹ $\left.\mathrm{BPM}\right)$ e 1 (um) médico legista (IML).

Assim, apreendendo a violência contra as mulheres como estrutural ${ }^{5}$ e pondo em questão a secundarização das mulheres na construção das políticas de segurança pública e com desconfiança na inclinação punitivista dos principais debates sobre o tema - os quais, não raras vezes, apontam para recrudescimento das punições e pela ampliação do rol de condutas criminalizáveis (ANDRADE, 2016) -, realizamos uma breve aproximação ao debate da segurança pública na atualidade. Em seguida, é feita uma análise do atendimento às mulheres em situação de violência pelas instituições de Segurança Pública do município de Parintins, que evidencia os limites institucionais (de infraestrutura, recursos humanos e da própria constituição normativa e legal) no trato dessa questão e provoca questionamentos sobre a crescente demanda por medidas policialescas e punitivistas envidando o enfrentamento à violência.

\section{Aproximações ao debate da Segurança Pública na atualidade}

A segurança pública não é uma questão nova no Brasil. Desde o período colonial, prevalece o interesse das classes dominantes dentro de uma ordem militarizada, sendo o serviço público da segurança utilizado para atender a interesses privados. Contudo, o reconhecimento pelo Estado e pela burguesia das desigualdades produzidas na sociedade capitalista e a luta de classes que dela deriva provocaram tensionamentos importantes nas instituições. Este processo impôs respostas às expressões da "questão social", principalmente no século XX, entre as quais, a exigência de segurança como direito de cidadania, ainda que acompanhado do controle social e ideológico (SANTOS, 2017).

subvaloriza as violências decorrentes normalmente das relações afetivo-familiares e que ocorrem no ambiente doméstico; 2) quando a mulher é sujeito ativo do delito, a criminologia feminista evidenciou o conjunto de metarregras que produzem o aumento da punição ou o agravamento das formas de execução das penas exclusivamente em decorrência da condição de gênero (CAMPOS; CARVALHO, 2011, p. 153).

3 Parintins é a segunda cidade mais populosa do Amazonas, concentrando 115. 363 habitantes. Está localizada no extremo leste do estado, à margem direita do Rio Amazonas, distante cerca de 369 quilômetros de Manaus (INSTITUTO BRASILEIRO DE GEOGRAFIA E ESTATÍSTICA, 2020).

4 As entrevistas foram realizadas mediante assinatura de Termo de Consentimento Livre Esclarecido TCLE pelos/as interlocutores/as, que aceitaram participar voluntariamente do estudo, autorizando o registro em áudio e a divulgação dos dados com identificação do cargo/função.

5 A violência contra as mulheres é estrutural dada sua naturalização, invisibilidade, alcance e magnitude, ao se confundir mesmo com o modo de ser da sociedade patriarcal-racista-capitalista, atingindo, de forma direta ou indireta, todas as mulheres nos mais variados contextos (BARROSO, 2018).

Argum., Vitória, v. 12, n. 3, p. 69-85, set./dez. 2020. | ISSN 2176-9575 
Do ponto de vista hegemônico, a segurança da sociedade é um requisito à garantia de direitos e ao cumprimento de deveres. Conforme destacam Carvalho e Silva (2011), ela aparece como demanda social que necessita de um sistema de estruturas estatais, demais organizações da sociedade e de uma política de segurança constituída por instituições ou órgãos estatais que se materializam através de planos e programas responsáveis pela adoção de ações direcionadas à segurança individual e coletiva da sociedade. Os autores afirmam a ineficiência desse sistema em garantir essa segurança e elucidam que, apesar de haver uma redução da intervenção do Estado neoliberal no âmbito social, na segurança pública, tem ocorrido uma ampliação de investimentos nos instrumentos de controle sobre a sociedade, o que, nos termos de Wacquant (2008), se configura como um Estado brutalmente punitivo, ancorado na força policial e no aparato legal.

Para Wacquant (2008), o Estado Penal ou a criminalização da pobreza e da miséria se estabelece pela "[...] insegurança social gerada em toda parte pela dessocialização do trabalho assalariado, o recuo das proteções coletivas e a 'mercantilização' das relações humanas" (WACQUANT, 2008, p. 13). Para o autor, o paradoxo existente entre o menos Estado econômico e social, subsidiado pelo neoliberalismo, e o mais Estado policial e penitenciário concretiza e fomenta a insegurança social generalizada da qual somos, simultaneamente, vítimas e algozes.

É necessário destacarmos que o processo de emergência da agenda neoliberal se assenta em um contexto de explicitação da crise estrutural do capital (MÉSZÁROS, 2009), resultando em consequências ao chamado "mundo do trabalho" e no acirramento das profundas desigualdades sociais. Portanto, a agudização das ações de controle e punição pelo Estado decorrem, em grande medida, da precarização do trabalho e deterioração das relações sociais de produção, impostas pelo neoliberalismo, que atende aos interesses do mercado. Atesta-se a afirmação feita por Carvalho e Silva (2011), que “[...] temos, assim, um 'Estado para os pobres', com menos assistência e mais controle e vigilância e um 'Estado para os ricos', que possibilita menos controle sobre a reprodução econômica [...]” (CARVALHO; SILVA, 2011, p. 61), direcionando formas de penalização a sujeitos diferenciados, sendo ao lado do mercado, o maior provedor da violência estrutural que compõe o contexto contemporâneo (WACQUANT, 2008).

Assim, os governos contribuem para que o Estado sirva aos poucos "donos do poder" em detrimento da soberania do povo, ao adotarem ações de repressão às manifestações das desigualdades estruturais através da institucionalização de processos de criminalização de segmentos sociais e exclusão das possibilidades do mercado (CARVALHO; SILVA, 2011). Campos (1999) ratifica que a criminologia crítica questiona o sistema penal e revela um dos principais pilares sobre os quais se assenta a criminalização: a seletividade. Para a autora, "[...] o sistema penal passa a ter a função social de reproduzir as relações sociais e de manter a estrutura vertical da sociedade e os processos de marginalização [...]" (CAMPOS, 1999, p. 14), sendo visto como um violador de direitos.

Argum., Vitória, v. 12, n. 3, p. 69-85, set./dez. 2020. | ISSN 2176-9575 
No que tange ao debate sobre as mulheres, Vera Regina Pereira de Andrade (1999), referência no debate sobre criminologia crítica feminista no Brasil, analisa o Estado Penal como um meio ineficaz para a proteção das mulheres contra a violência, uma vez que duplica a violência exercida contra as mulheres e as divide, sendo uma estratégia excludente, que afeta a própria unidade do movimento de mulheres. Para a autora, as mulheres esperam do sistema penal a punição da violência, o que conduz a uma situação paradoxal, pois essa demanda pelo sistema penal acaba por reunir o movimento de mulheres, que é um dos movimentos mais progressistas do país, com um dos movimentos mais conservadores e reacionários, que é o movimento de Lei $e$ Ordem (ANDRADE, 1999). Nesta direção, Karam (2015) destaca que "[...] ativistas e movimentos feministas que aplaudem e reivindicam o rigor penal contra os que apontam como responsáveis por violências contra mulheres, acabam por paradoxalmente reafirmar a ideologia patriarcal" (KARAM, 2015, p. 3). Ou seja, segmentos do movimento feminista buscam se libertar da dominação masculina recorrendo à proteção de um sistema demonstradamente classista, sexista e racista.

Essa é a tese que fundamenta o pensamento de Angela Davis (2019), ao afirmar que o encarceramento nunca resolveu o problema da violência. Para a autora, se "[...] o que devemos fazer é simplesmente encarcerar essas pessoas para, então, eliminar a violência de gênero, na verdade, estamos colaborando ativamente na continuidade da reprodução da violência que estamos tentando erradicar" (DAVIS, 2017, p. 2). Ao criticar as polícias e o sistema judicial no mundo, Davis (2017) defende o chamado "abolicionismo penal" ${ }^{6}$, por entender que existe uma relação entre encarceramento em massa e escravidão que, na verdade, reforça um "instrumento de perpetuação da violência", e não o combate a ela7.

A despeito disso, cotidianamente, as instituições policiais são buscadas por mulheres que vivem situações de violência (MACHADO, 2002; PASINATO; SANTOS, 2008), esperando uma ação mediadora, proteção e solução por parte da polícia. A denúncia nas instituições de segurança pública, principalmente, nas delegacias - especializadas ou não -, se tornou orientação unânime nos manuais de enfrentamento à violência contra as mulheres no Brasil. Reflexo da ausência de um sistema de proteção social, a segurança pública nestes casos assumiu o protagonismo como a solução fim e, quase sempre, única para a questão.

Por outro lado, apesar da criação de instituições, manuais de atendimento e legislações nos últimos anos no Brasil - Lei Maria da Penha (11.340/2006), Lei do Feminicídio

\footnotetext{
${ }^{6}$ Por abolicionismo penal, entende-se as alternativas abolicionistas que perturbam as relações de crime e punição, raça e punição, gênero e punição, sem se restringir ao sistema prisional como uma instituição isolada, mas como parte de todas as relações sociais e institucionais que sustentam a permanência da prisão (DAVIS, 2019).

7 Segundo dados do Departamento Penitenciário Nacional (Depen) (2019), a população carcerária brasileira é de 755.274 pessoas, considerando as unidades prisionais e outras carceragens. Desse total, 711.080 (95,06\%) são homens e 36.929 (4,94\%), mulheres. Do total de homens, 321.172 têm entre 18 e 29 anos e, ainda, 417.042 são negros ou pardos, com baixa ou nenhuma escolaridade. Do total de mulheres, 13.860 têm de 18 a 29 anos e, ainda, 21.299 são negras ou pardas, com baixa ou nenhuma escolaridade. Por fim, $229.823(30,43 \%)$ do total correspondem a presos provisórios, ou seja, pessoas que se encontram cerceadas em sua liberdade sem terem sido julgadas.
} 
(13.104/2015) e Lei de Importunação Sexual (13.718/2018) -, não se pode negar o descaso em relação às ações de segurança pública e da justiça nas situações de violência contra as mulheres, o que contribui para altos índices de impunidade. Conforme aponta Pasinato (2012), as mulheres denunciam a violência, mas "[...] o Estado não reage à essa denúncia, ou se reage, fica apenas no papel. Essa ineficiência cria um cenário de impunidade muito perverso" (PASINATO, 2012, não paginado).

Entretanto, não fazemos coro com as análises que consideram a impunidade como determinação da violência ou motivo para a sua persistência, mas atestar a morosidade e a impunidade nos casos de violência contra as mulheres no Brasil, dado o perfil patriarcal das sentenças judiciais (que muitas vezes colocam a mulher como provavelmente culpada, em razão da naturalização da violência), é importante para questionar a visão de que a luta do feminismo pelo fim da violência no país tem contribuído para o Estado Penal. Neste sentido, a dificuldade de acesso à segurança e justiça pelas mulheres põe em questão as análises que, de forma simplista e insidiosa, responsabilizam o encarceramento em massa em curso no país à luta feminista pela criminalização da violência.

\section{Atendimento às mulheres em situação de violência nas instituições de Segurança Pública no município de Parintins (AM)}

A Norma Técnica de Padronização das Delegacias de Atendimento à Mulher (BRASIL, 2010) preconiza que as atividades das delegacias têm caráter preventivo e repressivo, “[...] devendo realizar ações de prevenção, apuração, investigação e enquadramento legal, as quais devem ser pautadas no respeito aos direitos humanos e aos princípios do Estado Democrático de Direito" (BRASIL, 2010, p. 10). Em virtude disso, categoriza o atendimento às mulheres, em quatro fases: 1) corresponde ao atendimento inicial e ao acolhimento das mulheres: elas devem ser atendidas em espaço separado do/a agressor/a, de forma reservada, para manter a privacidade da mulher; 2 ) diz respeito ao esclarecimento sobre os direitos da mulher e informações referentes aos serviços de atendimento às mulheres em situação de violência existentes no município; 3) refere-se ao registro da ocorrência realizado pela mulher. Nesta etapa, são coletadas todas as provas relacionadas ao crime, para instaurar o Inquérito Policial (IP); e, no final deste processo, o caso é encaminhado ao Judiciário; e 4) corresponde ao monitoramento das ocorrências, no qual a delegacia deve fornecer informações às mulheres sobre o andamento do seu processo.

A DECCM em Parintins não dispõe de prédio próprio, funciona no mesmo prédio da $3^{0}$ DIP, portanto, alguns serviços são compartilhados pelas instituições, como é o caso dos registros dos Boletins de Ocorrência (B.O. $)^{8}$. Sobre isso a delegada argumenta:

a gente tá tentando melhorar cada vez mais o atendimento e principalmente tentar fazer esse atendimento de forma reservada. No último ano, a gente já tá fazendo o B.O dentro da sala dos cartórios. É uma opção que as vítimas têm, principalmente as vítimas de violência sexual e os demais casos infelizmente

\footnotetext{
8 Conforme relatório da DECCM de Parintins, entre 2016 e 2019, foram registrados 8.780 B.O., o que indica uma média de seis denúncias de violência contra mulheres por dia no município, nos últimos quatro anos.
} 
ainda continuam sendo aí na frente na permanência, realmente pela falta de servidores mesmo. (DELEGADA CIVIL, PESQUISA DE CAMPO, 2019).

A fala da delegada é reveladora da precariedade da estrutura física e de recursos humanos de que a DECCM dispõe para assumir o atendimento às mulheres vítimas de violência, a exemplo dos registros dos B.O. em geral que ficam a cargo dos/as plantonistas da $3^{\text {a }}$ DIP, sendo o atendimento realizado de forma integral pela DECCM apenas nos casos de violência sexual. Nestas situações, ao chegar à recepção, as vítimas são encaminhadas para uma escuta mais reservada na sala do cartório.

Além disso, nos finais de semana e feriados, a DECCM não presta serviço, deixando as mulheres que procuram a delegacia sem atendimento especializado, posto que o atendimento fica a cargo da $3^{\underline{a}}$ DIP. Cabe destacar ainda, por ocasião da observação e registro em diário de campo, a prática comum de requisitar os/as estagiários/as ${ }^{9}$ para realização dos registros de boletim de ocorrência, sendo que a responsabilidade para tal função deveria ser de uma "[...] equipe de policiais qualificados profissionalmente, preferencialmente do sexo feminino, com compreensão do fenômeno da violência de gênero" (BRASIL, 2010, p. 37). Ressalta-se que a ausência de qualificação profissional para atender as demandas de violência contra as mulheres "[...] determina a prevalência de práticas díspares, pautadas mais no bom senso do que em uma perspectiva profissional [...]" (SILVA, 1992, p. 129), contribuindo para a revitimização das mulheres e fragmentação do atendimento.

Vale evidenciar também que o investimento no Estado Penal, referido no item anterior, sequer possibilita aprimorar a infraestrutura das instituições de segurança pública ou a qualificação de seus agentes para o atendimento às mulheres em situação de violência, o que implica uma secundarização dessa pauta no campo do sistema punitivista.

Identificamos ainda a falta de privacidade para as mulheres durante a denúncia de violência, o que fere os princípios de uma escuta sigilosa e não julgadora. Segundo a delegada, isso acontece

[...] porque a demanda é grande e a gente às vezes acaba atendendo dois casos na mesma sala, mas aí como acaba que são casos de mulheres, uma acaba no final conversando com a outra, ouvindo um pouquinho o problema da outra e as coisas acabam dando certo no atendimento (DELEGADA CIVIL, PESQUISA DE CAMPO, 2019).

Nessa narrativa, verificamos que o tratamento dispensado às mulheres não condiz com a normatização, pois este deve ocorrer de forma humanizada, em ambiente adequado, com sala reservada durante sua permanência no serviço, caracterizando-se no descaso em torno da violência contra as mulheres. Além disso, essa realidade aponta para outro aspecto relacionado à realidade dos atendimentos às mulheres: a violência institucional, aqui entendida como uma dimensão da violência estrutural contra as mulheres, "[...] aquela exercida pelos agentes estatais nos serviços públicos, por ação

9 Graduandos/as dos cursos de Administração e Serviço Social.

Argum., Vitória, v. 12, n. 3, p. 69-85, set./dez. 2020. | ISSN 2176-9575 
ou omissão [...]" (BARROSO, 2018, p. 219) ou a perpetuação e reprodução mesma da violência pelo próprio Estado por meio de suas instituições (BARROSO, 2018).

Durante a entrevista, a delegada chamou a atenção para o fato de as mulheres denunciarem a situação de violência, chegando a registrarem os boletins de ocorrência, mas que acabam desistindo de dar prosseguimento do processo à justiça.

[...] infelizmente ainda há um grande número de desistência, no ano passado foi um pouco mais de 700 boletins de ocorrências registrados e cerca de 130 inquéritos enviados à justiça, ou seja, desse número a gente percebe que ainda há um grande número de mulheres que desistem de fazer o procedimento de encaminhar o procedimento a justiça, mas, pelo menos assim, o B.O já é uma vitória, pelo menos já está ali registrado e a maioria desses B.Os são de ações privadas, que é quando dependem da vítima. São aquelas situações de injúria, de ameaça que as mulheres desistem de dar continuidade no procedimento (DELEGADA CIVIL, PESQUISA DE CAMPO, 2019).

É importante salientar que no Brasil as mulheres não se sentem seguras em denunciar os agressores às autoridades competentes, mesmo havendo serviços de apoio disponíveis, devido à falta de efetividade dos órgãos, a exemplo da precariedade das delegacias especializadas em acompanhar e em apoiar a vítima (FRANCO; NOGUEIRA; GRANDIM, 2014). Portanto, os profissionais que lidam com a problemática da violência carecem de uma formação que os possibilite buscar estratégias que contemplem e respeitem as particularidades e a complexidade de cada experiência. Essa formação permitiria a instrumentalização dos "[...] quadros policiais para uma compreensão e intervenção mais crítica e competente diante do fenômeno da violência contra as mulheres" (SILVA, 1992, p. 171).

Em relação à $3^{\underline{a}}$ DIP, no que tange à dinâmica de atendimento às mulheres, "[...] elas têm o primeiro contato com o servidor plantonista e este, ao vislumbrar estas ocorrências, faz contato com o delegado ou com a delegada e encaminham a mulher para ser ouvida e verificar que medidas serão tomadas" (DELEGADO CIVIL, PESQUISA DE CAMPO, 2019). A fala destaca, de forma geral, a dinâmica de atendimento às mulheres pela instituição e indica a ausência de um atendimento especializado neste caso. Essas lacunas nas delegacias podem contribuir para um atendimento desqualificado às vítimas e desmotivação para a realização da denúncia, embora as delegacias especializadas também apresentem falhas no atendimento.

Durante o período da pesquisa, foram observados alguns atendimentos para registro de B.O. por parte dos plantonistas da $3^{\mathrm{a}} \mathrm{DIP}^{10}$, que, de forma pouco complacente, repassam informações para a população, principalmente para as mulheres que chegam para realizar denúncias. Um dos exemplos mais emblemáticos foi o de uma mulher, acompanhada de seu filho (criança), que buscou a delegacia para registrar boletim de ocorrência sobre violência doméstica. Durante o atendimento, a criança começou a chorar e o plantonista falou com a mulher de forma impaciente para ela fazer a criança parar de chorar. No momento, havia várias pessoas na recepção, onde são registradas

10 Os atendimentos observados referem-se ao momento do registro dos B.O. na recepção da instituição. Conforme destacado, os B.O. são feitos no espaço da recepção ou sala de espera da $3^{\text {a }}$ DIP, sem garantia de privacidade ou sigilo das informações.

Argum., Vitória, v. 12, n. 3, p. 69-85, set./dez. 2020. | ISSN 2176-9575 
as ocorrências, e que presenciaram aquela situação. Foi nítido o constrangimento daquela mulher.

A situação descrita, salienta a importância da formação dos/as profissionais para o atendimento especializado às mulheres em situação de violência, pois, a ausência de capacitação pode levar o/a policial a considerar que a violência contra a mulher, sobretudo o conflito conjugal, não é de competência da polícia, embora prevista como crime no Código Penal (SILVA, 1992). Para Silva (1992), as instituições policiais são permeadas por práticas abjetas, estereotipadas, fundadas e reproduzidas a partir da simbiose patriarcado-racismo-capitalismo, que promovem representações preconceituosas, inspirando discursos e práticas classistas, racistas e sexistas, suscitando posturas altamente discriminatórias, sobretudo em relação às mulheres.

A ausência de formação para o atendimento especializado às mulheres nas instituições policiais foi apontada na pesquisa, a saber, no caso da $3^{\underline{a}}$ DIP e DECCM, os/as entrevistados/as relataram que, além de não serem convidados/as para atividades dessa natureza (cursos, eventos, capacitações), não teriam tempo disponível em razão da dinâmica do trabalho. Desse modo, evidencia-se que a necessidade de formação permanente desses/as profissionais acaba sendo, em alguma medida, apreendida como um elemento externo ao trabalho desenvolvido por esses sujeitos, não reconhecida, portanto, como parte integrante de sua própria dinâmica laboral. Tal fato pode dificultar a mitigação de algumas debilidades resultantes da peculiaridade do atendimento à violência contra as mulheres. Por outro lado, exige considerar a situação de precariedade do trabalho desses/as profissionais e a expectativa social em torno da instituição policial (SANTOS, 2017), que acaba por contribuir para a legitimação da reprodução da violência nesse espaço. Estas visões e práticas sociais expressam contradições da demanda por segurança pública como solução para a insegurança e violência contra as mulheres.

Em relação ao atendimento e acolhimento às mulheres em situação de violência pelo $11^{\circ}$ BPM, de acordo com o tenente-coronel:

Há um chamado para o nosso 190, um registro, uma solicitação. Nós deslocamos a viatura até o local dessa ocorrência, dessa solicitação, e de lá o policial atende essa ocorrência e vê a necessidade, qual é o tipo de infração no local. Às vezes é apenas uma solicitação de orientação, mas às vezes já é uma agressão mesmo e aí nesse caso eles são conduzidos, tanto ela, como vítima, e ele, como infrator, para a delegacia para que lá ocorra o processo normal.

(TENENTE-CORONEL, PESQUISA DE CAMPO, 2019).

Percebemos que o atendimento é parcial, acontecendo somente quando há solicitação por meio do disque denúncia - 190. Quando há essa solicitação, a Polícia Militar se desloca até o local da denúncia para averiguar a situação. Se julgarem necessário, fazem o encaminhamento dos envolvidos até a delegacia. Algumas vezes o chamado da Polícia Militar é para a realização de orientações, o que implica na importância do conhecimento dos/as profissionais referentes às questões de violência contra as mulheres, posto que o atendimento adequado e qualificado é uma ferramenta indispensável no acolhimento, proteção e, principalmente, no encorajamento das

Argum., Vitória, v. 12, n. 3, p. 69-85, set./dez. 2020. | ISSN 2176-9575 
mulheres, uma vez que exprimem sentimentos de vergonha, humilhação e medos, que caracterizam a tensão e as dificuldades de falar sobre a situação vivida (HANADA; D'OLIVEIRA; SCHRAIBER, 2010). Nesse sentido, destacamos a importância da promoção de ações preventivas e comunitárias pela Polícia Militar em relação à violência contra as mulheres, ainda que a estrutura da instituição não favoreça medidas dessa natureza, posto que privilegia ações ostensivas de caráter repressivo e violento ${ }^{11}$.

$\mathrm{O} 11^{\underline{0}}$ BPM não possui um espaço físico para o atendimento às mulheres vítimas de violência, mas de acordo com o tenente-coronel, "[...] espera-se conseguir um espaço específico no prédio do Batalhão para receber também as denúncias de violência através da criação do projeto Ronda Maria da Penha" (PESQUISA DE CAMPO, 2019). A Ronda Maria da Penha ${ }^{12}$ preconiza a capacitação de policiais militares para o atendimento às mulheres vítimas de violência doméstica e familiar, a garantia das Medidas Protetivas de Urgência, na discussão e repressão ao descumprimento de ordem judicial e, por fim, no encaminhamento das mulheres à Rede de Atendimento à Mulher Vítima de Violência Doméstica no âmbito municipal ou estadual. Apesar de enfatizar a importância desse projeto quando solicitado, o tenente-coronel não dispunha de mais informações sobre o assunto. Ao que indica, o projeto busca promover ações preventivas, em caráter prioritário, articulando com medidas repressivas, destinadas à proteção às mulheres.

Por sua vez, o IML desempenha um papel importante no atendimento às mulheres em situação de violência, principalmente às vítimas de violência física e sexual, fazendo a coleta ou validação das provas recolhidas e demais providências periciais do caso (VIVIAN; ANGONESE, 2015). Faz-se importante mencionar a Lei 13.721/18 (BRASIL, 2018), que prioriza o exame de corpo de delito às mulheres vítimas de violência doméstica, às crianças, adolescentes, idosos e pessoas com deficiência. No que se refere ao atendimento e acolhimento às mulheres em situação de violência pela instituição, de acordo com o médico legista:

Todo exame é realizado a essas mulheres quando solicitado pelo Judiciário, pela $3^{\underline{a}}$ DIP ou pela Delegacia da Mulher. Existe uma sala apropriada aqui no Hospital Jofre Cohen que é a sala do SAVVIS, tem uma pessoa que acompanha, um familiar que acompanha. Então sempre isso é testemunhado e depois colocado no relatório (MÉDICO LEGISTA -IML, PESQUISA DE CAMPO, 2019).

\footnotetext{
${ }^{11}$ Vale ressaltar que, enquanto a Polícia Militar é responsável pelo policiamento ostensivo e sua atuação visa evitar a perturbação da ordem pública, através de medidas preventivas e de policiamento ostensivo - sendo os policiais militares considerados pela Constituição como força auxiliar e reserva do Exército e, por isso, estruturada, operacionalmente, de maneira similar ao Exército, organizada em comandos intermediários, batalhões, companhias e pelotões -, a Polícia Civil intervém quando os fatos que se constituem infrações penais não puderam ser evitados, atuando assim, na investigação das infrações penais e apuração da respectiva autoria (SULOCKI, 2007).

${ }^{12}$ A Ronda Maria da Penha foi criada em 2015 em Salvador, Bahia, a partir de um termo de cooperação técnica entre as Secretarias Estaduais de Políticas para as Mulheres (SPM-BA) e de Segurança Pública (SSP), Defensoria Pública, Ministério Público e Tribunal de Justiça da Bahia, tendo em vista o número elevado de vítimas de violência doméstica na cidade (BAHIA, 2015).
}

Argum., Vitória, v. 12, n. 3, p. 69-85, set./dez. 2020. | ISSN 2176-9575 
A fala do médico legista indica que o atendimento às mulheres pelo IML só acontece mediante a solicitação do poder judiciário ou das delegacias do município. Existe uma sala apropriada no Hospital Jofre Cohen para o atendimento às vítimas de violência sexual (espaço do Serviço de Assistência às Vítimas de Violência Sexual (SAVVIS)), onde são acompanhadas por um/a familiar durante os procedimentos ${ }^{13}$. Os demais casos, como os de violência física, são atendidos no prédio do IML, situado ao lado do hospital. Ressalta-se que os serviços do SAVVIS, apesar de não comporem a segurança pública e, sim, a saúde, também são destinados para as vítimas de violência sexual que são encaminhadas ao IML. A equipe multidisciplinar desse serviço é composta por enfermeiras/os, ginecologistas, infectologistas, assistentes sociais e psicólogas/os. De acordo com o Médico Legista, as vítimas muitas vezes vêm encaminhadas da delegacia para realizar o exame no IML e para o atendimento especializado do SAVVIS. Ele considera esta etapa fundamental para o fortalecimento do atendimento especializado, uma vez que os profissionais específicos do IML não recebem capacitação específica de atendimento às mulheres vítimas de violência.

A Lei Maria da Penha preconiza ainda o trabalho em rede entre as instituições de segurança pública, e dessas com instituições que compõem a rede de atendimento mais ampla, prevista na Política Nacional de Enfrentamento à Violência (Assistência Social, Saúde, Educação e Justiça) para orientar o atendimento aos casos de violência doméstica e familiar contra as mulheres (BRASIL, 2011). Nesse sentido, questionamos os/as profissionais das instituições sobre as relações estabelecidas entre as instituições em que trabalham e as demais que compõem a segurança pública, bem como dessas com as demais instituições da rede de atendimento.

\begin{abstract}
Nós não temos nenhum tipo de informação, não fomos procurados por nenhuma instituição, apenas, como eu falei no início, atendemos a ocorrência, encaminhamos para a Delegacia Especializada de Violência contra a Mulher e essa delegacia faz todo o processo e encaminhamento para outros tipos de atendimento, na justiça e em outros setores, mas nós não temos o retorno daquela ocorrência, não fazemos reuniões, não participamos de reunião para tratar especificamente sobre isso daí, não somos convidados, mas se formos convidados iremos poder atuar da melhor forma. (TENENTE-CORONEL - $11^{\circ}$ BPM, PESQUISA DE CAMPO, 2019).
\end{abstract}

A gente trabalha com plantão, mas só para B.O., a gente não tem aquela equipe para realmente tá todo tempo ali para atender aquela vítima, mas a polícia militar todos os dias praticamente apresenta algum autor de violência doméstica ou familiar. Então, a vítima aciona geralmente pela linha direta e traz o agressor aqui para a delegacia para, se for o caso, fazer o flagrante ou então iniciar o inquérito policial. O delegado de polícia emite a requisição de corpo de delito ou de conjunção carnal ou coito anal e o perito do IML vai fazer esse exame para realmente comprovar a materialidade do delito, ele vai transcrever tudo num laudo que vai ser anexado aos autos e encaminhado à justiça como meio de prova. Para outras instituições, nós encaminhamos geralmente para o CREAS para atendimento psicológico, para o CRAS, quando a gente observa que ela se encaixa em algum benefício social e para a

${ }^{13}$ Serviços disponíveis no SAVVIS: acolhimento, exames clínicos e ginecológicos, coleta de vestígios, contracepção de emergência, profilaxias para HIV, IST e Hepatite B, exames complementares, acompanhamento social e psicológico, e seguimento ambulatorial (BRASIL, 2015).

Argum., Vitória, v. 12, n. 3, p. 69-85, set./dez. 2020. | ISSN 2176-9575 
Defensoria Pública (DELEGADA CIVIL - DECCM, PESQUISA DE CAMPO, 2019).

Com relação à violência doméstica, há casos em que o agressor é apresentado pela polícia militar que vai e traz as partes envolvidas até a delegacia, se necessário já encaminha a vítima para o hospital para o atendimento e apresenta o autor nesta delegacia. Aí, o delegado analisa a situação. Vê se cabe a prisão em flagrante e instaura o procedimento e toma as medidas cabíveis. Com relação ao IML, é encaminhada a vítima para fazer o exame de corpo de delito que é a prova material do crime. As vítimas também são encaminhadas para amparo nos órgãos de assistência social" (DELEGADO CIVIL - $3^{\underline{a}}$ DIP, PESQUISA DE CAMPO, 2019).

Toda agressão ela é registrada na polícia, ou é feito uma queixa no judiciário para que seja feito o exame de lesões corporais, ou seja, culmina como o exame de corpo de delito. A pessoa lesionada, agredida faz um Boletim de Ocorrência. Nesse Boletim de Ocorrência, geralmente é registrado o que tá acontecendo, as marcas que ficaram da agressão e são encaminhadas para fazer o exame (MÉDICO-PERITO - IML, PESQUISA DE CAMPO, 2019).

Constata-se uma dinâmica estabelecida com base em encaminhamentos padrões nos casos de violência contra a mulher. Quando a denúncia é direcionada à Polícia Militar, esta vai até o lugar solicitado e, se for necessário, encaminha o/a agressor/a e a/as vítima/s para a DECCM (que ficará detido/a na delegacia, em caso de crime em flagrante) para o registro do B.O. e formalização da denúncia. A partir do momento em que o caso chega à delegada, esta avalia a necessidade de encaminhar ou não a vítima para os serviços do IML, em casos de suspeita/acusação de agressão física e/ou violência sexual. Quando encaminhado ao IML, o Médico Legista realiza os exames necessários ou encaminha para o SAVVIS quando se trata de violência sexual. Após os procedimentos, o laudo pericial é encaminhado para a delegada para que seja anexado ao processo judicial e encaminhado ao juiz. Alguns casos de violência não são encaminhados pela PM, mas registrados/denunciados diretamente na $3^{\frac{\mathrm{a}}{}}$ DIP.

A partir dos relatos, verificamos que as instituições interagem apenas através de encaminhamentos, sem o posterior acompanhamento dos casos. Nos chama atenção a fala do tenente-coronel da Polícia Militar, que relata que a instituição realiza apenas atendimento e encaminhamento dos casos de mulheres, não existindo diálogo entre as instituições, reuniões para construir estratégias de prevenção e enfrentamento à violência contra as mulheres entre os órgãos de segurança pública. Destaca-se, portanto, a centralidade dos encaminhamentos, mas, sem diálogo, acompanhamento ou retorno desses.

Quanto aos encaminhamentos para as instituições da rede de atendimento, o $11^{\circ}$ BPM, $3^{\text {a }}$ DIP e IML deixam a cargo da DECCM orientar e encaminhar as mulheres aos serviços da rede de atendimento. Quando perguntado sobre o conhecimento de outras instituições e serviços da rede de atendimento às mulheres, os/as profissionais (com exceção da equipe da DECCM) não responderam ou não souberam identificar os serviços, sinalizando apenas como órgãos da assistência social. As falas são reveladoras da centralidade conferida à DECCM nos casos de violência contra as mulheres, o que

Argum., Vitória, v. 12, n. 3, p. 69-85, set./dez. 2020. | ISSN 2176-9575 
pode ser atribuído à inexistência de outros serviços especializados na rede de atendimento no município.

Neste sentido, Parintins não dispõe de serviços especializados para as mulheres, tais como Casas-abrigo, Centros de Referência, Centros de Reabilitação e Educação do Agressor, Juizados de Violência Doméstica e Familiar contra a Mulher, Defensorias da Mulher, que subsidiem o atendimento da Rede de Segurança Pública (BRASIL, 2011). A ausência desses serviços especializados indica um privilegiamento das ações de cunho punitivista pelo Estado ao limitar o enfretamento à violência contra as mulheres ao campo da segurança pública. Ao mesmo tempo, confirma a desproteção e maior exposição das mulheres pela ausência dessa rede de proteção, configurando outra expressão da violência institucional, qual seja, a garantia pelo Estado das condições para que as desigualdades (que determinam a violência) se manifestem.

\section{Conclusão}

Ao analisar o atendimento às mulheres em situação de violência pelas instituições de Segurança Pública em Parintins a partir da criminologia crítica feminista, podemos explicitar o desafio de problematizar a questão, relacionando-a às determinações mais amplas da própria violência e de não cair em armadilhas, tais como considerar a segurança pública de forma descolada ou autonomizada do sistema judicial. Diferente disso, a análise indica a importância de se apreender as contradições tanto da demanda por medidas cada vez mais policialescas e/ou punitivas no enfrentamento à violência contra as mulheres, como do descaso destas instituições no atendimento às mulheres, evidenciando os limites da polícia e da política punitivista do sistema judicial no trato dessas questões.

A pesquisa evidencia que as instituições de segurança possuem infraestrutura bastante precarizada, não contando com espaços próprios ou adequados e, tampouco, com pessoal qualificado para o atendimento às mulheres vítimas de violência que buscam seus serviços. Destaca-se principalmente a DECCM, que, por ser considerada um serviço especializado, deveria dispor de um espaço próprio e funcionários/as capacitados/as para o atendimento às mulheres em situação de violência.

Além da capacitação dos/as profissionais das instituições que atendem mulheres em situação de violência, da indicação de realização de ações preventivas pela Polícia Militar, a pesquisa aponta para a importância da criação de espaços específicos no IML com equipe técnica qualificada para o atendimento às mulheres em situação de violência, uma vez que o SAVVIS - serviço de apoio - acolhe apenas vítimas de violência sexual, deixando as demais mulheres que precisam do IML sem atendimento especializado.

Apesar de destacarmos estas possibilidades como alternativas para qualificar o atendimento e o trabalho entre as instituições de segurança, de modo a permitir a construção de mecanismos de tensionamento à revitimização das mulheres nos atendimentos, compreendemos que estas instituições estão vinculadas ao sistema penal que, como já problematizamos, é um meio incapaz de garantir segurança e 
proteção às mulheres, porque é ele próprio um sistema de produção e reprodução da violência institucional inscrita nas relações patriarcais-racistas-capitalistas, que exerce seu poder e seu impacto sobre as vítimas. Em outros termos, as instituições de segurança pública são parte desse sistema que, mesmo propondo segurança a toda sociedade, em último caso, opera com base na vigilância, controle e punição para a garantia da ordem de alguns.

A despeito disso, destacamos que uma rede bem articulada de serviços (especializados e não especializados) que não se limite ao âmbito da segurança é um passo relevante para mitigação dos efeitos da violência contra as mulheres. Porém, somente se constrói uma rede ampla e diversificada quando há a horizontalidade de responsabilidades e compromissos entre todas as partes envolvidas. Por isso, se torna necessária a ampliação dos serviços especializados e a criação de uma política e um sistema de proteção às mulheres ampliado, com vistas ao aperfeiçoamento do atendimento por meio do trabalho em rede das diversas políticas sociais presentes no município de Parintins. Ademais, mesmo que o atendimento às mulheres vítimas de violência não deva se restringir ao âmbito da segurança pública, essa ainda se constitui como uma das principais portas de entrada para as mulheres aos demais serviços de atendimento, o que torna ainda mais importante discutir essa questão.

Por fim, tanto a problematização da criminalização da violência como a ausência de medidas para a proteção das mulheres devem ser pontos centrais nos debates feministas, dado que somente o combate ao sexismo (incluindo a heteronormatividade), o racismo, e outras estruturas de relações sociais de classes e de exploração-opressão poderão levar, em última instância, ao pleno enfrentamento da violência contra as mulheres.

\section{Referências}

ANDRADE, Vera Regina Pereira de. Criminologia e Feminismo: da mulher como vítima à mulher como sujeito. In: CAMPOS, Carmen Hein (Org.). Criminologia e Feminismo. Porto Alegre: Editora Sulina, 1999. Cap. 3, p. 105-117.

ANDRADE, Camila Damasceno de. Por uma criminologia crítica feminista. Revista Espaço Acadêmico, Maringá, v. 16, n. 183, p. 14-25, ago. 2016.

BAHIA. Secretaria de Políticas para as Mulheres.. Ronda maria da penha. Salvador, 2015. Disponível em:

http://www.mulheres.ba.gov.br/modules/conteudo/conteudo.php?conteudo=36\#: :tex $\mathrm{t}=$ Criada\%2oem\%2omar\%C3\%A70\%2ode\%202015,Justi\%C3\%A7a\%2oe\%2ose\%2oconsol idou\%20como. Acesso em: 9 jun 2020.

BARROSO, Milena Fernandes. O começo do fim do mundo: violência estrutural contra mulheres no contexto da hidrelétrica de Belo Monte. 2018. 385p. Tese (Doutorado em Serviço Social) - Faculdade de Serviço Social. Universidade do Estado do Rio de Janeiro, Rio de Janeiro, 2018.

Argum., Vitória, v. 12, n. 3, p. 69-85, set./dez. 2020. | ISSN 2176-9575 
BRASIL. Presidência da República. Lei no 13.721, de 2 de outubro de 2018. Altera o Decreto-Lei no 3.689, de 3 de outubro de 1941 (Código de Processo Penal), para estabelecer que será dada prioridade à realização do exame de corpo de delito quando se tratar de crime que envolva violência doméstica e familiar contra mulher ou violência contra criança, adolescente, idoso ou pessoa com deficiência. Diário Oficial na União, Brasília (DF), 2 out. 2018. Disponível em: http://www.in.gov.br/materia//asset_publisher/KujrwoTZC2Mb/content/id/43716638. Acesso em: 12 jun. 2018.

BRASIL. Secretaria Nacional de Enfrentamento à Violência contra as Mulheres; Secretaria de Políticas para as Mulheres - Presidência da República. Rede de Enfrentamento à violência contra as mulheres. Brasília (DF), 2011.

BRASIL. Ministério da Saúde; Ministério da Justiça; Secretaria de Políticas para as Mulheres. Norma técnica: atenção humanizada às pessoas em situação de violência sexual com registro de informações e coleta de vestígios. Brasília (DF), 2015.

BRASIL. Secretaria de Políticas para as Mulheres/Presidência da República; Secretaria Nacional de Segurança Pública; Ministério da Justiça. Norma Técnica de Padronização das Delegacias Especializadas de Atendimento às Mulheres. Brasília (DF), 2010.

CAMPOS, Carmen Hein. Introdução. In: CAMPOS, Carmen Hein. Criminologia e Feminismo. Porto Alegre: Editora Sulina, 1999. p. 13-17.

CAMPOS, Carmen; CARVALHO, Salo. Tensões atuais entre a Criminologia Feminista e a Criminologia Crítica: a experiência brasileira. In: CAMPOS, Carmen. (Org.). Lei Maria da Penha: Comentada em uma Perspectiva Jurídico-Feminista. Rio de Janeiro: Lumen Juris, 2011.

CARVALHO, Vilobaldo Adelídio de; SILVA, Maria do Rosário de Fátima. Política de segurança pública no Brasil: avanços, limites e desafios. Katálysis, Florianópolis, v. 14, n. 1, p. 59-67, 2011.

DAVIS, Angela. Estarão as prisões obsoletas? Rio de Janeiro: Difel, 2019.

DAVIS, Angela. O encarceramento em massa nunca trouxe soluções para conter a violência. Huffpost Brasil, 26 jul. 2017. Disponível em:

https://www.huffpostbrasil.com/2017/o7/26/angela-davis-o-encarceramento-emmassa-nunca-resolveu-ou-troux_a_23050036/. Acesso em: 9 jun. 2020.

DEPARTAMENTO PENITENCIÁRIO NACIONAL. Levantamento nacional de informações penitenciárias - Infopen. Brasília (DF), 2019. Disponível em: https://app.powerbi.com/view?r=eyJrIjoiZWI2MmJmMzYtODA2MCooYmZiLWI442It NDU2ZmIyZjFjZGQoIiwidCI6ImViMDkwNDIwLTQoNGMtNDNmNyo5MWYyLTRiO GRhNmJmZThlMSJ9 . Acesso em: 18 jun. 2020. 
FRANCO, Telma Lucas Borges; NOGUEIRA; Denismar Alves; GRANDIM, Clícia Valim Cortês. Violência contra a mulher: levantamento dos registros policiais em um município de Minas Gerais/Brasil. Cienc. Cuid. Saúde, Belo Horizonte, v. 13, n. 2, p. 302-308, abr./jun. 2014.

HANADA, Heloisa; D'OLIVEIRA, Ana Flávia Pires Lucas; SCHRAIBER, Lilia Blima. Os psicólogos na rede de assistência a mulheres em situação de violência. Revista Estudos Feministas, Florianópolis, v. 18, n. 1, p. 33-6o, 2010.

INSTITUTO BRASILEIRO DE GEOGRAFIA E ESTATÍSTICA. Cidades e Estados. Brasília (DF), 2020. Disponível em: https://www.ibge.gov.br/cidades-eestados/am/parintins.html. Acesso em: 17 set 2020.

KARAM, Maria Lúcia. Os paradoxais desejos punitivos de ativistas e movimentos feministas. Justiticando, 13 mar. 2015. Disponível em:

http://www.justificando.com/2015/o3/13/os-paradoxais-desejos-punitivos-de-ativistase-movimentos-feministas/. Acesso em: 12 jun. 2020.

MACHADO, Lia Zanotta. Atender vítimas, criminalizar violências: dilemas das delegacias da mulher. Série Antropologia, Brasília (DF), série 319, p. 1-23, 2002.

MÉSZÁROS, István. Para além do capital: rumo a uma teoria de transição. São Paulo, Boitempo Editorial, 2009.

PASINATO, Wania. Impunidade desafia combate à violência contra a mulher no Brasil: analistas dizem que Judiciário e falta de estruturas são principais obstáculos. G1, São Paulo, 25 nov. 2012. Disponível em:

http:/g1.globo.com/brasil/noticia/2012/11/impunidade-desafia-combate-a-violenciacontra-mulher-no-brasil.html. Acesso em: 18 jun. 2020.

PASINATO, Wania; SANTOS, Cecília MacDowell. Mapeamento das delegacias da mulher no Brasil. Núcleo de Estudos de Gênero, Campinas, p. 1-38, 2008.

RESENDE, Leandro. 15 dados sobre a segurança pública que todo mundo deveria saber. Folha de São Paulo, São Paulo, 2 ago. 2018. Disponível em: https://piaui.folha.uol.com.br/lupa/2018/o8/o2/15-dados-seguranca-publica/. Acesso em: 23 jun 2020.

SANTOS, Paulo Roberto Felix dos. A cidadania negada: traços de uma trajetória inconclusa dos trabalhadores policiais militares no Brasil. Curitiba: Editora Prismas, 2017.

SILVA, Marlise Vinagre. Violência contra a mulher: quem mete a colher? São Paulo: Cortez, 1992. 
SULOCKI, Victoria-Amália de B. C. G. de. Segurança Pública e Democracia: Aspectos Constitucionais das Políticas Públicas de Segurança. Rio de Janeiro: Lumen Juris, 2007.

VIVIAN, Chancarlyne; ANGONESE, Amanda Saraiva. Além do Que se Vê: a atuação dos profissionais do Instituto Médico-Legal (IML) em um ambiente onde a vida começa, transcorre e termina (2015). Disponível em:

https://psicologado.com.br/atuacao/psicologia-da-saude/alem-do-que-se-ve-aatuacao-dos-profissionais-do-instituto-medico-legal-iml-em-um-ambiente-onde-avida-comeca-transcorre-e-termina. Acesso em: 12 jun. 2020.

WACQUANT, Loic. As prisões da miséria. São Paulo: Zahar, 2008.

Milena Fernandes BARROSO. Autora e revisora.

Doutora em Serviço Social pela Universidade do Estado do Rio de Janeiro (2018), com estágio doutoral na Universidade do Québec, Canadá (2015). Professora do curso de Serviço Social da Universidade Federal do Amazonas, no Instituto de Ciências Sociais, Educação e Zootecnia e do Programa de PósGraduação em Serviço Social e Sustentabilidade na Amazônia (PPGSS). Atualmente desenvolve o projeto de pesquisa "Violência contra as mulheres na universidade: uma análise nas instituições de ensino superior no Amazonas" (2019-2021), financiado pela Fundação de Amparo à Pesquisa do Amazonas (FAPEAM).

Raissa Ribeiro LIMA. Coautora e revisora.

Assistente Social, graduada pela Universidade Federal do Amazonas, no Instituto de Ciências Sociais, Educação e Zootecnia (2019). Pesquisadora pela Fundação de Amparo à Pesquisa do Estado do Amazonas (Fapeam).

Argum., Vitória, v. 12, n. 3, p. 69-85, set./dez. 2020. | ISSN 2176-9575 